\title{
Erratum to: Stress concentration around a strongly oblate spheroidal cavity in a transversely isotropic medium
}

\author{
Chun-Ron Chiang
}

Published online: 22 May 2015

(C) Springer Science+Business Media Dordrecht 2015

\section{Erratum to: International Journal of Fracture 119: L91-L97, 2003 DOI 10.1023/A:1024952702152}

Springer publishers would like to apologize for the omission of the last article page of "Stress Concentration Around a Strongly Oblate Spheroidal Cavity in a Transversely Isotropic Medium" by Professor Chun-Ron Chiang, printed and online in The International Journal of Fracture, Volume 119, Issue 4, 2003 , pp. L91-L97. Please find below the missing article page content that should be regarded by the reader as part of the final version.

for this type of cavity, in contrast with the isotropic case, $K_{t}$ depends on the elastic modulus. A relation between the stress intensity factor $K$ of a penny shaped crack and the crack tip stress is established via the stress rounding factor $\Omega$, Eq. (19). The stress rounding factor is explicitly determined. Numerical values for some hexagonal single crystals are calculated and given in Table 1.

The online version of the original article can be found under doi:10.1023/A:1024952702152.

\section{C.-R. Chiang ( $)$}

Department of Power Mechanical Engineering, National

Tsing Hua University, HsinChu 30013, Taiwan

e-mail: crchiang@pme.nthu.edu.tw

\section{References}

Benthem JP (1987) Stresses in the region of rounded corners. Int J Solids Struct 23:239-252

Chen WT (1968) Axisymmetric stress field around spheroidal inclusions and cavities in a transversely isotropic material. J Appl Mech 35:770-773

Chiang CR (1991) Stress field around a rounded crack tip. J Appl Mech 58:834-836

Chiang CR (1995) Addendum: the stress field for a blunt crack in an anisotropic material. Int J Fract 70:R99

Chiang CR (1998) Stress concentration factors of edge-notched orthotropic plate. J Strain Anal 33:395-398

Chiang CR (1999) On stress concentration factors in orthotropic material. J Chin Inst Eng (Taiwan) 22:301-305

Chiang CR (2002) On the Eshelby tensor in a transversely isotropic material (unpublished manuscript)

Creager M, Paris PC (1967) Elastic field equations for blunt cracks with reference to stress corrosion cracking. Int $\mathrm{J}$ Fract 3:247-252

Eshelby JD (1957) The determination of the elastic field of an ellipsoidal inclusion and related problems. Proc R Soc Lond A241:376-396

Eshelby JD (1961) Elastic inclusions and inhomogeneities. In: Sneddon IN, Hill R (eds) Progress in solid mechanics. North Holland, Amsterdam

Green AE, Zerna W (1968) Theoretical elasticity. Clarendon Press, Oxford

Hill R (1961) Discontinuity relations in mechanics of solids. In: Sneddon IN, Hill R (eds) Progress in solid mechanics. North Holland, Amsterdam

Kassir MK, Sih GC (1975) Three dimensional crack problems. Noordhoff, Leyden

Mura T (1987) Micromechanics of defects in solids. Martinus Nijhoff, The Hague

Nye JF (1985) Physical properties of crystals. Clarendon Press, Oxford 
Pan YC, Chou TW (1976) Point force solution for an infinite transversely isotropic solid. J Appl Mech 43:608-612

Reid CN (1973) Deformation geometry for material scientists. Clarendon Press, Oxford

Sneddon IN (1946) The distribution of stress in the neighbourhood of a crack in an elastic solid. Proc R Soc Lond A187:229-260

Sternberg E (1958) Three dimensional stress concentrations in the theory of elasticity. Appl Mech Rev 11:1-4
Walpole LJ (1981) Elastic behavior of composite materials: theoretical foundations. Adv Appl Mech 21:169-242

Withers PJ (1989) The determination of the elastic field of an ellipsoidal inclusion in a transversely isotropic medium and its relevance to composite materials. Philos Mag A 59:759781 